\title{
Characteristics of Foamed Concrete Utilizing Rice Husk Ash with Foam Percentage Variation
}

\author{
Saloma $^{\#}$, Hanafiah ${ }^{\#}$, Tiara Maelta Amanda ${ }^{\#}$, Anggun Suci Budiarti ${ }^{\#}$ \\ ${ }^{\#}$ Civil Engineering Department, Faculty of Engineering, Sriwijaya University, South Sumatera, Indonesia \\ E-mail: saloma_571@yahoo.co.id, hanafiah_dr@yahoo.com.sg
}

\begin{abstract}
Foamed concrete is one of the lightweight concrete innovations without coarse aggregates by adding foam to concrete mortar mixtures. The concrete was developed as a non-structural element in the building. This research utilizes rice husk ash (RHA) as a substitute material for cement. This study determines the effect of foam percentage and the use of rice husk ash (RHA) on foamed concrete's microstructures. The percentage of used foam is $30 \%, 40 \%, 50 \%$, and $60 \%$, while the percentage of RHA substitution is $5 \%, 10 \%, 15 \%$ and $20 \%$ on cement. The use of RHA is to show the secondary reaction of cement to make new CSH. Tests conducted in this study include fresh concrete test, the compressive strength of 28 days, and SEM test. The fresh concrete test includes the slump flow test and setting time. Research shows that the value of slump flow decreases with increasing percentage of foam and RHA substitution on cement. Percentage foam 30\% to concrete volume with RHA 0\% shows the maximum slump flow value that is $63.25 \mathrm{~cm}$. Setting time test results are increasing as the percentage of foam and substitution of RHA increases. The maximum setting time value is on $60 \%$ foam to concrete volume with RHA $20 \%$. Percentage foam $30 \%$ with RHA $10 \%$ showed the maximum compressive strength value of 28 days at $7.77 \mathrm{MPa}$ with density $1,378 \mathrm{~kg} / \mathrm{m}^{3}$ and air void/bubble structure with the smallest diameter.
\end{abstract}

Keywords - foamed concrete; rice husk ash; characteristics; microstructure.

\section{INTRODUCTION}

Foamed concrete is one of lightweight concrete composed of cement, water, sand, and foams. The difference between foamed concrete and the other concretes is the use of aggregate that is replaced by foam, which distributes a homogeneous air bubble to form a stable pore on concrete. Foamed concrete utilizes solid air bubbles, produced by foam that create a very lightweight concrete to reduce concrete density. The reduced density make foamed concrete compressive strength smaller than other concrete. ([1]-[2]) states that research of foam concrete began by J. A. Eriksson in 1923 [3].

The method of foamed concrete production, foamed concrete is divided into two groups [4]. The first group is by using a foaming agent (physically foamed concrete), and the other is by adding the powder of aluminum (chemically aerated concrete) [5]. Foamed concrete based on its forming method is divided into three methods, by chemical reaction (air-entraining method), foam formation outside of the concrete mix (foamed method) and stabilizing the air by chemical reaction [6].

ACI 523.3R states that preformed foam produced using compressors outside the concrete mix by mixing foaming agent with water. The foam that has been produced will be mixed with mortar [7]. To determine the mixed proportion was based on ACI 523.3R. Previous research from [8]-[9] stated that mix proportion of foamed concrete was selected based on mixed trials with three parameters, such as the ratio of cement water, the ratio of sand cement, and density of the mixture [10].

ACI $523.3 \mathrm{R}$ states that the proportion of the mixture begins with the selection of density for wet concrete, cement content, and the cement-water ratio. The proportion of the mixture then can be calculated based on the absolute volume method. The sum of the absolute volume of cement, water, and aggregate to $1 \mathrm{~m} 3$ of concrete. The relationship between air volume and foam volume can be determined based on the foam weight, as described in ASTM C-769 [11].

The research indicates five percentage of foam volume, $30 \%-70 \%$ of the concrete volume [12]-[13]. This research, conclude that the lower percentage of foam added to the concrete will increase its compressive strength and density, the higher foam percentage, on the other hand, will decrease its density and compressive strength.

Rice husk ash is the result of burning rice husk. After many research performed by experts, it turns out that the greatest content in rice husk ash is silicates. The addition of RHA can increase the strength of the concrete. The reaction 
between silica $(\mathrm{SiO} 2)$ in rice husk ash with calcium hydroxide $(\mathrm{Ca}(\mathrm{OH}) 2)$ which is the product of cement hydration produce a new calcium silicate hydrate (CHS). Calcium Silicate Hydrate (CHS) is stronger on the concrete [14]-[15].

By $w / c=0.60$ and cement-sand ratio 0.25 , there is an increase in 28-day normal foamed concrete compressive strength with foamed concrete with the addition of rice husk ash [16]. The substitution of rice husk ash with the excellent composition can increase the compressive strength, whereas if the substitution exceeds the maximum limit, it reduces the compressive strength of the concrete.

In general, pores are defined as volumes in concrete unfilled by solid phases. In concrete, the pores are formed because the product of the cement hydration process cannot fill the overall volume. In concrete microstructure, pores can be divided by size, i.e., gel $(1.5 \mathrm{~nm})$, capillary and contraction $(1.3 \mu \mathrm{m})$, and air micropore $(25-500 \mu \mathrm{m})$. In general microstructure, foamed concrete can be seen in foam distribution. SEM (Scanning electron microscopy) test can determine pore size and foam distribution in foamed concrete.

\section{MATERIAL AND METHOD}

In this research, the foam percentage used is $30 \%, 40 \%$, $50 \%$, and $60 \%$ from concrete volume, and the percentage of rice husk ash substitution used are $0 \%, 10 \%, 15 \%$ and $20 \%$ on cement. The materials used in this research are cement, fine aggregate, and rice husk ash as an admixture, water, and foaming agent. Materials used in this research are cement, fine aggregate, water, rice husk ash, and foaming agent.

The cement used in this research is OPC (Ordinary Portland Cement) type 1 . The fine aggregate used is the natural sand of Tanjung Raja, Palembang, South Sumatera, Indonesia. The sand used passes No. 16 sieve. According to the ASTM standard, the maximum size of fine aggregate is $1.8 \mathrm{~mm}$. Water used in concrete mixtures should be clean, should not contain oil, sludge, acids, organic substances or other materials that can damage the concrete.

TABLE I

CHEMiCAL COMPOSITION OF RHA

\begin{tabular}{|c|l|c|}
\hline No. & \multicolumn{1}{|c|}{ Composition } & Weight (\%) \\
\hline 1. & Silicon Dioxide $\left(\mathrm{SiO}_{2}\right)$ & 93.12 \\
\hline 2. & Aluminum Oxide $\left(\mathrm{Al}_{2} \mathrm{O}_{3}\right)$ & 0.96 \\
\hline 3. & Iron (III) Oxide $\left(\mathrm{Fe}_{2} \mathrm{O}_{3}\right)$ & 0.32 \\
\hline 4. & Calcium Oxide $(\mathrm{CaO})$ & 1.77 \\
\hline 5. & Magnesium Oxide $(\mathrm{MgO})$ & 0.63 \\
\hline 6. & Sulfur Trioxide $\left(\mathrm{SO}_{3}\right)$ & 1.16 \\
\hline 7. & LOI & - \\
\hline
\end{tabular}

The rice husk ash (RHA) used in this research from PT. Putra Buyung Sembada, Palembang, South Sumatra, Indonesia. RHA must pass No. 200 sieve. The chemical properties test of rice husk ash was done in PT. Semen Baturaja Palembang, and Scanning Electron Microscope (SEM) test was conducted at Pusat Survei Geologi Laboratory Bandung with 200x magnification. The chemical composition of RHA is shown in Table I and the SEM microstructure of RHA shown in Fig 1.

The foaming agent used in this research is the gel type of synthetic surfactant. The composition usage for foam manufacture is $1 \mathrm{~kg}$ foaming agent: 30 the mixing method used is a pre-formed foam method, by making a foam mixture outside the mortar. The pressure of foam generator is $35-40$ psi.

In this research, the determination of the foamed concrete mix proportions was based on ACI 523.3R and references from previous journals. The mixed composition of the material affects the density and compressive strength of foamed concrete. Foamed concrete mix proportions used is shown in Table II.

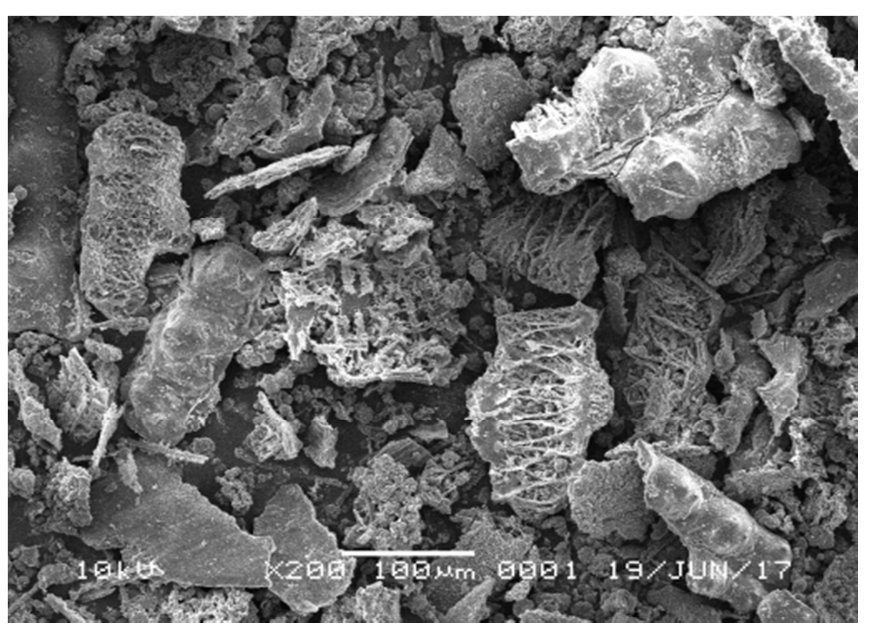

Fig. 1 SEM of rice husk ash (RHA)

TABLE II

Mix PROPORTIONS For $1 \mathrm{M}^{3}$ FOAMED CONCRETE

\begin{tabular}{|l|c|c|c|c|c|c|c|}
\hline \multirow{2}{*}{ Mixture } & PC & RHA & Foam & Water & Sand & \multicolumn{2}{|c|}{ Foam } \\
\cline { 2 - 8 } & $\mathbf{( k g )}$ & $\mathbf{( k g )}$ & (liter) & (liter) & (kg) & $\begin{array}{c}\text { FA } \\
(\mathbf{g r})\end{array}$ & $\begin{array}{c}\text { Water } \\
(\mathbf{k g})\end{array}$ \\
\hline 30V-0RHA & 592 & 0 & 300 & 296 & 592 & 484 & 15 \\
\hline 30V-10RHA & 533 & 59 & 300 & 296 & 592 & 484 & 15 \\
\hline 30V-15RHA & 503 & 88 & 300 & 296 & 592 & 484 & 15 \\
\hline 30V-20RHA & 474 & 118 & 300 & 296 & 592 & 484 & 15 \\
\hline 40V-0RHA & 513 & 0 & 400 & 257 & 513 & 645 & 19 \\
\hline 40V-10RHA & 462 & 51 & 400 & 257 & 513 & 645 & 19 \\
\hline 40V-15RHA & 436 & 77 & 400 & 257 & 513 & 645 & 19 \\
\hline 40V-20RHA & 411 & 103 & 400 & 257 & 513 & 645 & 19 \\
\hline 50V-0RHA & 435 & 0 & 500 & 217 & 435 & 806 & 24 \\
\hline 50V-10RHA & 391 & 43 & 500 & 217 & 435 & 806 & 24 \\
\hline 50V-15RHA & 369 & 65 & 500 & 217 & 435 & 806 & 24 \\
\hline 50V-20RHA & 348 & 87 & 500 & 217 & 435 & 806 & 24 \\
\hline 60V-0RHA & 356 & 0 & 600 & 178 & 356 & 968 & 29 \\
\hline 60V-10RHA & 320 & 36 & 600 & 178 & 356 & 968 & 29 \\
\hline 60V-15RHA & 302 & 53 & 600 & 178 & 356 & 968 & 29 \\
\hline 60V-20RHA & 285 & 71 & 600 & 178 & 356 & 968 & 29 \\
\hline
\end{tabular}




\section{RESULT AND DISCUSSION}

\section{A. Slump Flow}

This test was conducted to find out workability of produced foamed concrete. The value of slump flow is obtained using average diameter measurement from concrete distribution in four directions when the corn slump flow is lifted. Slump flow test results are shown in Fig 2 and Fig 3.

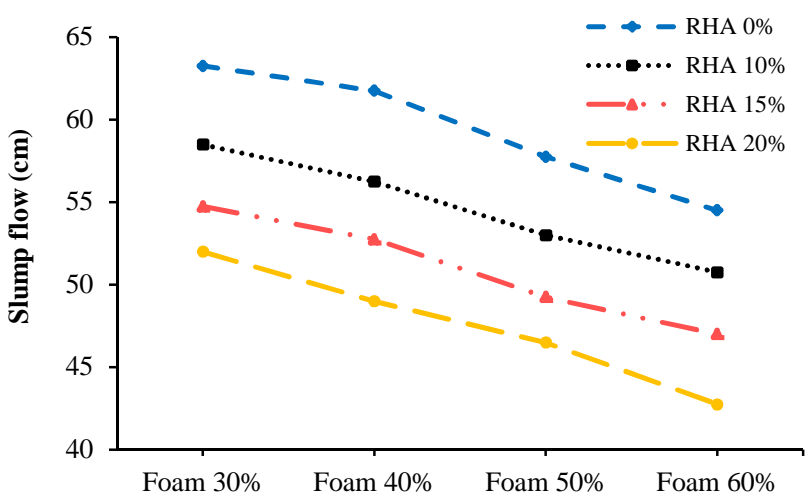

Foam composition

Fig. 2 The effect of foam composition on slump flow

Fig 2 shows that the maximum value of slump flow test is $63.25 \mathrm{~cm}$ with $30 \%$ foam mixture, and the minimum value of slump flow test is $42.75 \mathrm{~cm}$ with $60 \%$ foam to concrete volume. It shows that as the foam percentage increases, the value of slump flow decreases. This is due to the thick foam properties.

According to Fig 3, the slump flow test shows that the highest diameter of slump flow is in the mixture of RHA$0 \%$, and the lowest diameter of slump flow is in the RHA$20 \%$ mixture. The test results showed that the higher substitution of rice husk ash in foamed concrete makes slump flow diameter becomes smaller. This is due to the RHA water absorbs characteristic.

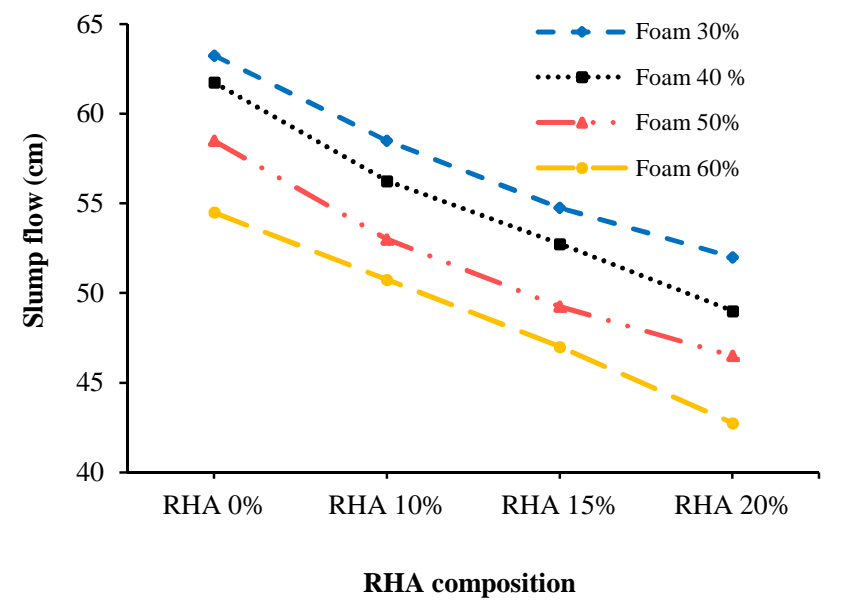

Fig. 3 The effect of RHA composition on slump flow

\section{B. Setting Time}

The result of setting time test for the effect of foam percentage is shown in Fig 4 and Fig 5, and the result of setting time test for the effect of RHA is shown in Fig 6 and Fig 7.
Based on Fig 4 and 5, it shows that the result of the initial setting time with 30\% foam ranges from 290-340 minutes, while the final time ranges from 610-650 minutes. Initial setting time with $40 \%$ foam ranges between 330-370 minutes, while the final setting time ranges from $690-750$ minutes. Initial setting time with $50 \%$ foam ranges from $380-420$ minutes, while the final time ranges from $770-790$ minutes.

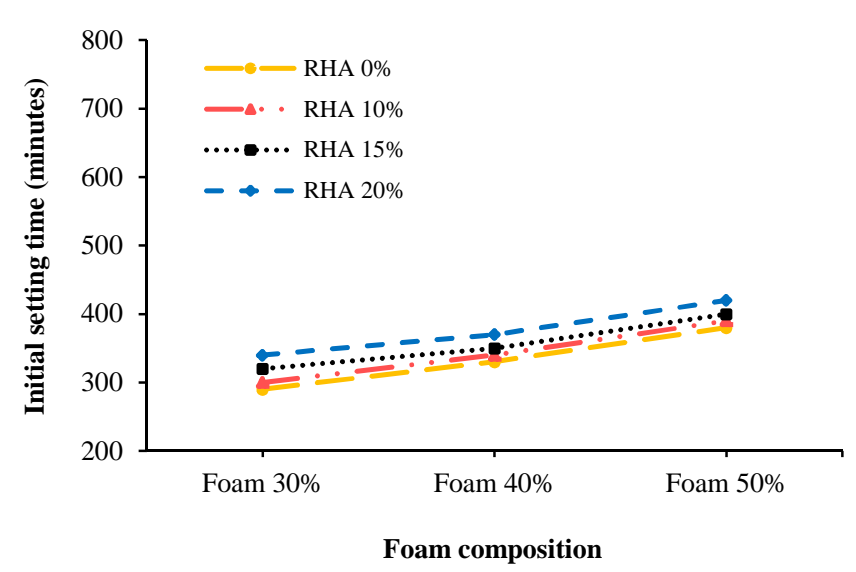

Fig. 4 The effect of foam composition on initial setting time

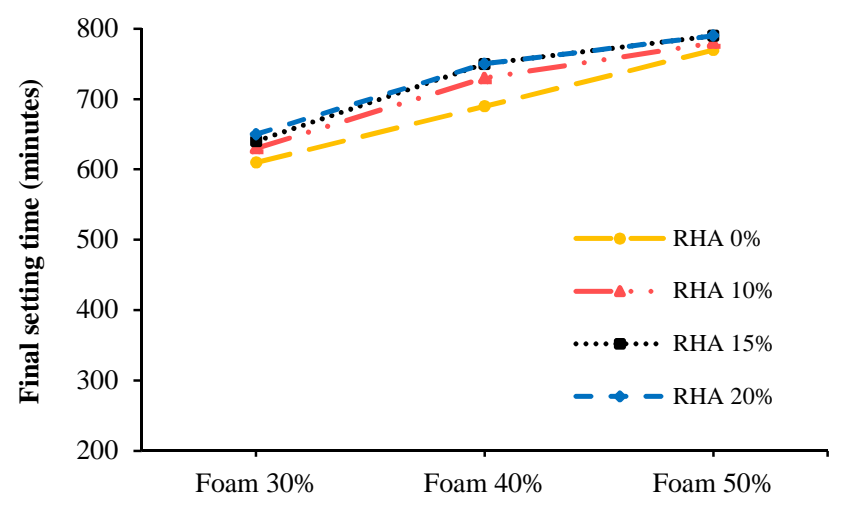

Foam composition

Fig. 5 The effect of foam composition on final setting time

The result shows that as the foam percentage increases, the value of the setting time for initial setting time and final setting time becomes longer. This is because the viscosity of fresh concrete is increasing as the amount of foam is getting higher in the concrete mixture, so it takes a longer time on the $50 \%$ foam percentage to harden.

The increase of foam percentage to actual volume significant affect on setting time. Based on Fig 6 and Fig 7 it shows that the result of the initial setting time with $0 \%$ RHA ranges from 290-380 minutes, while the final time ranges from 610-770 minutes. Initial setting time with 10\% RHA ranges from 300-390 minutes, while the final time ranges from 630-780 minutes. Initial setting time with 15\% RHA ranged between $320-400$ minutes, while the final setting time ranged from 640-790 minutes. Initial setting time with $20 \%$ RHA ranges from 340-420 minutes, and the final setting time ranges from $650-790$ minutes.

The longest time for final setting time is in the mixture of 50V15RHA and 50V20RHA, while the fastest time is in the mixture of 30V0RHA. The rice husk ash substitution did not 
significantly affect the setting time test. This shows that as the increase of RHA substitute, the result of final time becomes longer, its happened because with more RHA make concrete mixture difficult to binding.

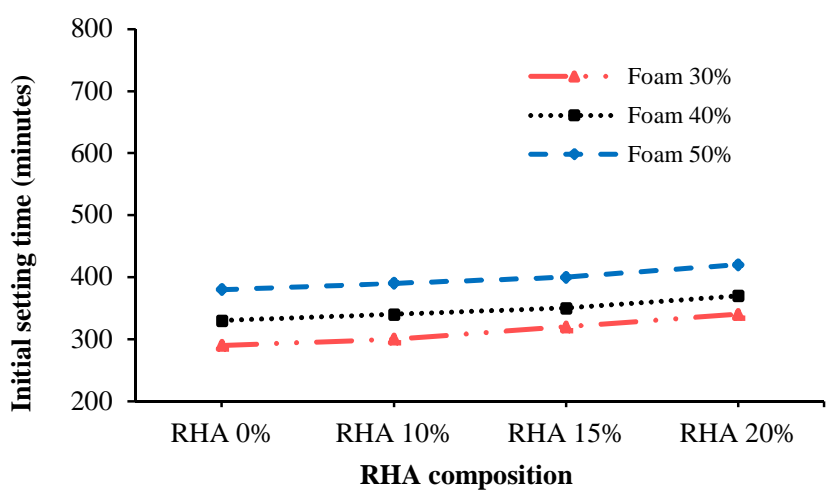

Fig. 6 The effect of RHA content on initial setting time

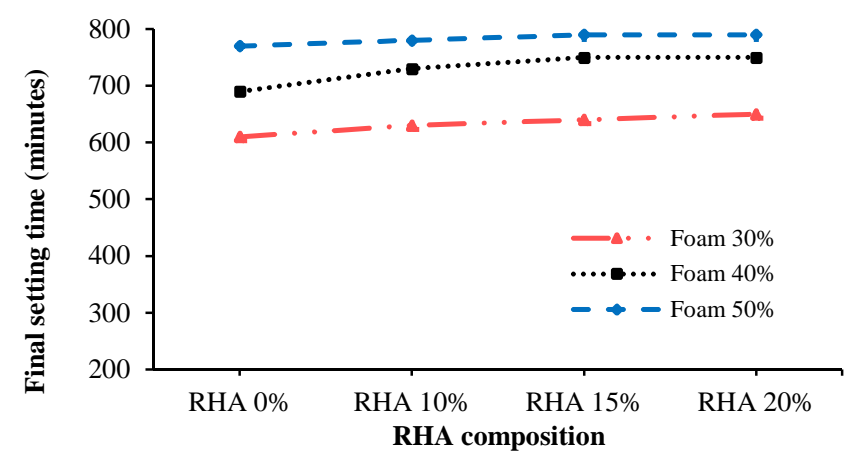

Fig. 7 The effect of RHA content for the final time on setting time

\section{Density}

The result of 28 days dry density are shown in Figure 8 and Fig 9. According to Fig 8, 30\% foam percentage gives the maximum density for all RHA substitution. While $60 \%$ foam percentage gives the minimum density for all RHA substitution. It shows that as the foam percentage increases, the value of density will decreases. This is due to foam as a replacement volume that has a mild period.

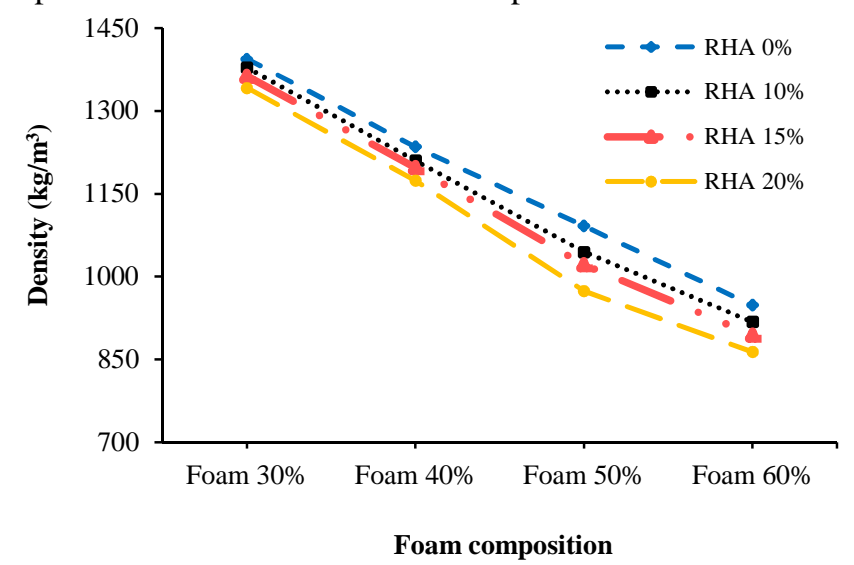

Fig. 8 The effect of foam composition on the density of 28 days

Fig 8 shows a decrease in density by increasing the percentage of foam in the concrete. The density result ranges from $850-1,400 \mathrm{~kg} / \mathrm{m}^{3}$. The decrease in density between foam percentages is significant, ranging between 110-200 $\mathrm{kg} / \mathrm{m}^{3}$. According to Fig 9, the higher rice husk ash substitution on cement can produce lighter density than concrete without rice husk ash substitution. This is due to the nature of RHA water absorbs characteristic. So that when the dry concrete a lot of water weight reduced.

Fig 9 shows that the affect of RHA to density on 28 days foamed concrete result ranged between 863.85-1,393.95 $\mathrm{kg} / \mathrm{m}^{3}$. The concrete density with $0 \%$ RHA is the heaviest, while the concrete density with $20 \%$ RHA is the lightest.

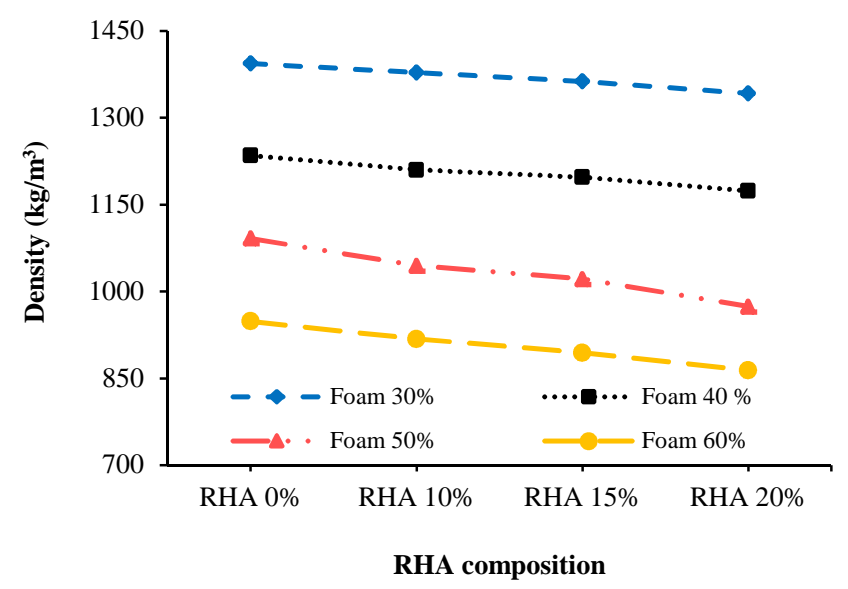

Fig. 9 The effect of RHA composition on the density of 28 days

\section{Compressive Strength}

Fig 10 and Fig 11 show the results of compressive strength test. According to Fig 10, 30\% foam percentage gives the optimum compressive strength for all RHA substitution.

Fig 10 shows that compressive strength result of 28 days is increasing by decreasing of foam percentage. The compressive strength of concrete with $30 \%$ foam ranged from 5.86-7.77 $\mathrm{MPa}$, while the compressive strength of concrete with $40 \%$ foam ranged from $4.60-7.14 \mathrm{MPa}$, then the compressive strength of concrete with $50 \%$ foam ranged between 1.78-3.44 MPa, and compressive strength of concrete with $60 \%$ foam ranged from $0.23-0.70 \mathrm{MPa}$.

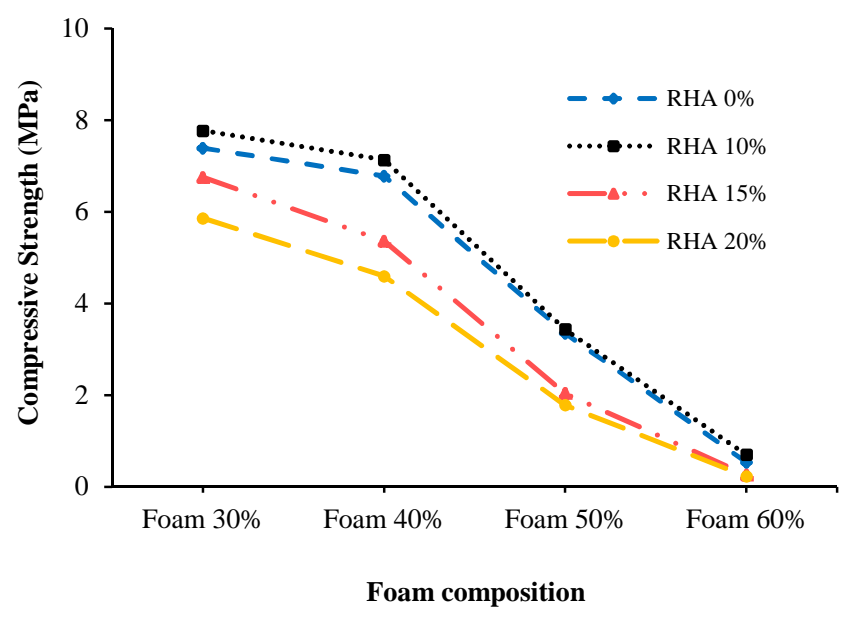

Fig. 10 The effect of foam composition on the compressive strength of 28 days 


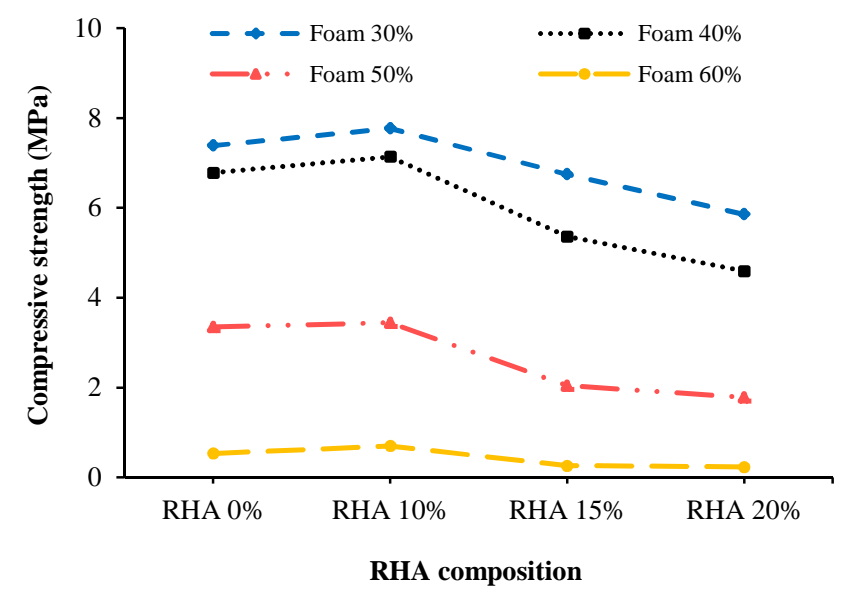

Fig. 11 The effect of RHA content on the compressive strength of 28 days

The maximum result of compressive strength with $30 \%$ foam is $7.77 \mathrm{MPa}$, and the minimum result of compressive strength with $60 \%$ foam is $0.23 \mathrm{MPa}$. This happens because, with the increasing percentage of foam added to the concrete mixture, the foamed concrete mixture becomes porous.

According to Fig 11, 10\% RHA substitution gives the optimum compressive strength for all foam percentage. The compressive strength of concrete with RHA $0 \%$ ranged from 0.53-7.39 $\mathrm{MPa}$, while RHA 10\% ranged from 0.70-7.77 $\mathrm{MPa}$, then RHA $15 \%$ ranged from $0.26-6.75 \mathrm{MPa}$, and with RHA $20 \%$ ranged between $0.23-5.86 \mathrm{MPa}$.

The maximum result of compressive strength with $10 \%$ rice husk ash substitution is $7.77 \mathrm{MPa}$, and the minimum result of compressive strength with $20 \%$ rice husk ash substitution is $0.23 \mathrm{MPa}$. At $0 \%$ rice husk ash substitution the compressive strength continues to rise until $10 \%$ rice husk ash substitution, it reaches the optimum substitution of rice husk ash. After that, the compressive strength decreases until 20\% rice husk ash substitution. Overmuch addition of rice husk ash makes a decrease in compressive strength because it can damage to chemical reactions in the concrete.

\section{E. Microstructure}

Microstructure test that has been done was Scanning Electron Microscope (SEM) test. The result of foamed concrete SEM test with 50x magnification is shown in Fig 9 to Fig 12. SEM samples obtained from compressive strength test at 28 days.

Fig 12(a) is foam concrete SEM of 30V-0RHA, seen many pores covered by a cement paste (bubble). The resulting bubble is spread evenly with sizes ranging from 18$220 \mu \mathrm{m}$, whereas there are several pores with width 50-100 $\mu \mathrm{m}$. Fig 12(b) is an SEM 30V-10RHA, pores and bubbles are present only at some point, and microcrack is visible at a width of fewer than $50 \mu \mathrm{m}$ occurring within the bubble. The largest pore width produced $98 \mu \mathrm{m}$. The pores and bubbles formed are fewer and smaller in size than the normal specimens. 30V-10RHA shows the most solid SEM images compared to normal specimens. This shows that there is an acceleration of secondary hydration reaction between $\mathrm{CH}$ and silica of RHA. SEM concrete is denser indicates the high compressive strength of concrete, according to data compressive strength foamed concrete 30V-10RHA has the highest compressive strength, that is $7.77 \mathrm{MPa}$.

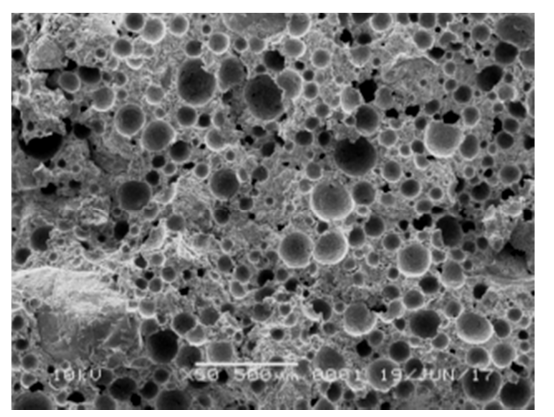

(a) 30V-0RHA

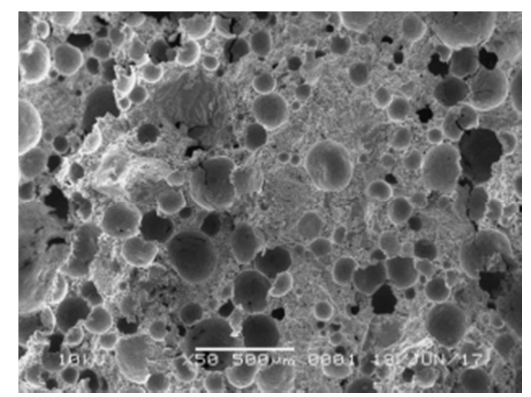

(b) $30 \mathrm{~V}-10 \mathrm{RHA}$

Fig. 12 The microstructure of foamed concrete with $30 \%$ foam

Fig 13(a) is foamed concrete SEM of 40V-0RHA, more pores are formed due to higher foam percentages. The bubble diameter is larger than the $30 \%$ foam percentage, which is between $54-450 \mu \mathrm{m}$. The pore width is about 150 $250 \mu \mathrm{m}$. Fig 13(b) show 40V-10RHA SEM, less pore due to the new CSH of the silica reaction from RHA with $\mathrm{CH}$ as cement hydration reaction. The result of $\mathrm{CSH}$ makes the concrete more solid than the concrete without RHA substitution.

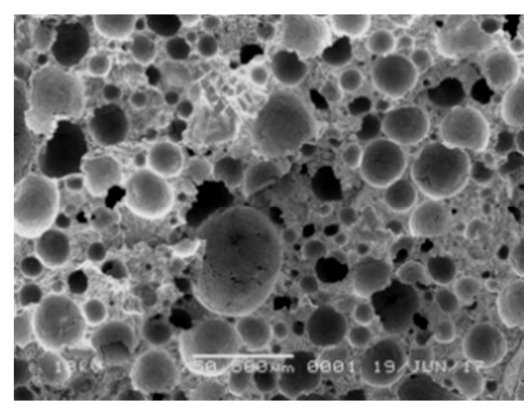

(a) 40V-0RHA

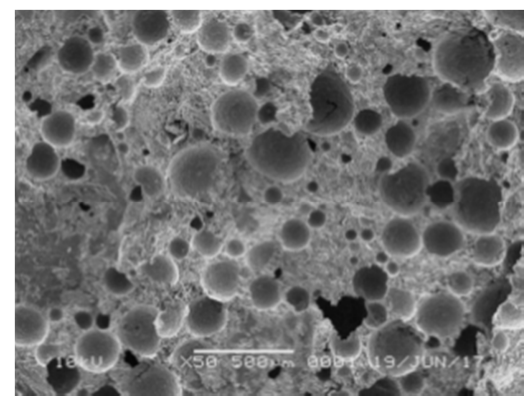

(b) 40V-10RHA

Fig. 13 Microstructure of foamed concrete with $40 \%$ foam 
Fig 14(a) is a foamed concrete SEM of 50V-0RHA, the size of the bubble diameter ranges from 71 to $571 \mu \mathrm{m}$. The pore width is $120-170 \mu \mathrm{m}$. Fig 14 (b) is an SEM of $50 \mathrm{~V}$ 10RHA, the pore becomes denser than the normal specimens. Pores formed between 30-170 $\mu \mathrm{m}$ wide and smaller than normal test specimens. This photo shows a closer bubble structure compared to normal specimens.

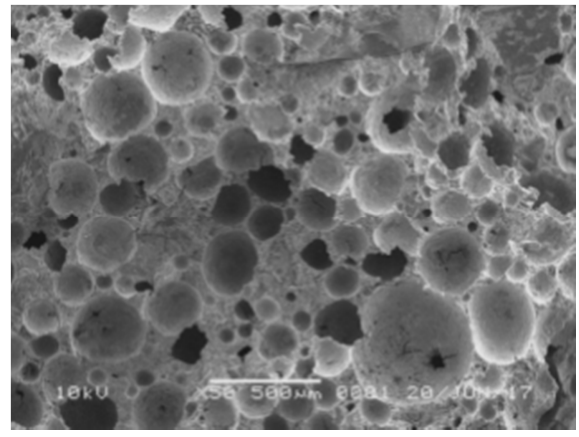

(a) 50V-0RHA

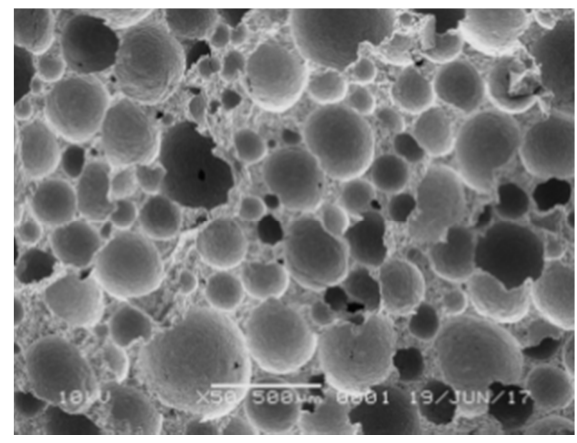

(b) 50V-10RHA

Fig. 14 Microstructure of foamed concrete with 50\% foam

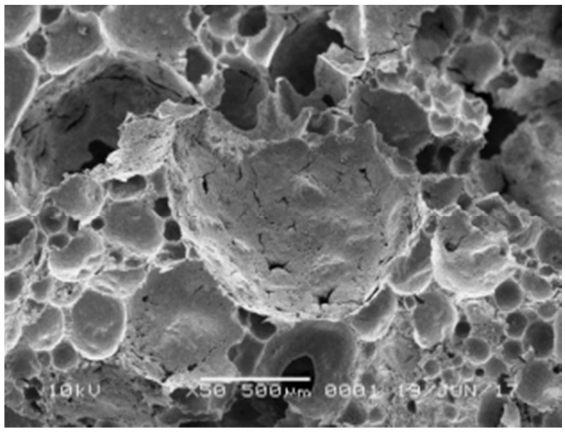

(a) 60V-0RHA

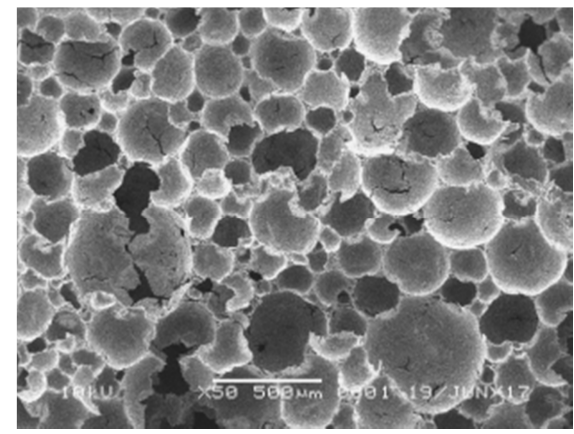

(b) $60 \mathrm{~V}-10 \mathrm{RHA}$

Fig. 15 Microstructure of foamed concrete with $60 \%$ foam
Fig 15(a) is foamed concrete SEM of 60V-0RHA, there are many pores with considerable size, and the bubble is no longer irregular. The concrete mix is no longer homogeneous. SEM shows a low compressive strength of concrete, according to compressive strength data foamed concrete 60V-0RHA has the lowest compressive strength, i.e., 0.23 MPa. Fig 15 (b) is an SEM 60V-10RHA, a more dense structure indicates that $\mathrm{CSH}$ has formed much more than a normal test object. The resulting bubble is denser than the normal specimens. The result bubble concrete with a $60 \%$ foam percentage is much larger than the other foam percentages. The size of bubble diameter ranges from 215 $535 \mu \mathrm{m}$.

\section{CONCLUSIONS}

The maximum percentage of foam and the increase of rice husk ash content used make a smaller slump flow value. The result of slump flow test in this research is ranged from $42.75-63.25 \mathrm{~cm}$, the maximum slump flow value is found in design mix 30V0RHA is $63.25 \mathrm{~cm}$, and minimum slump flow value is found in design mix 60V-20RHAis $42.75 \mathrm{~cm}$. The higher percentage of foams, the longer the concrete's time to bind. The increase of rice husk ash content in the concrete mix, the longer it takes concrete to bind. The result of setting time test in this study is the time needed for the concrete to binding, starting from the initial time ranging from 290-490 minutes, until the final time between 610-790 minutes. The fastest initial time and final time in $30 \mathrm{~V}-$ ORHA mix are $290 \mathrm{~min}$ and $610 \mathrm{~min}$, while the longest initial time and final time in 50V-20RHA are 420 minutes and 790 minutes

Based on the density result is found that with the higher percentage of foam and the increasing of rice husk ash substitutions used in the concrete mixture make the decrease in the density of the concrete. Based on the results of the compressive strength test is found that with the increasing of foam percentage added to the concrete mixture make compressive strength smaller. The foam percentage that produces the maximum compressive strength is $30 \%$ foam, whereas the foam percentage that produces the minimum compressive strength is $60 \%$ foam. Based on the results of the compressive strength test was found that the maximum compressive strength is in the $10 \%$ rice husk ash substitution, while the minimum compressive strength was found in $20 \%$ rice husk ash substitution. At $0 \%$ rice husk ash substitution the compressive strength continues to rise until $10 \%$ rice husk ash substitution, it reaches the optimum substitution of rice husk ash. After that, the compressive strength decreases until $20 \%$ rice husk ash substitution. The result of the highest compressive strength on the 28-day concrete was obtained at $30 \mathrm{~V}-10 \mathrm{RHA}$ is $7.771 \mathrm{MPa}$, and the lowest compressive strength was obtained at $60 \mathrm{~V}-20 \mathrm{RHA}$ is $0.22 \mathrm{MPa}$.

The optimum composition of the foamed concrete mixture with the percentage of $30 \%$ foam and RHA substitution as much as $10 \%$ result of most solid microstructure and smallest bubble diameter. For a $30 \%$ foam percentage with no rice husk ash substitution, the resulting bubble spreads evenly with sizes ranging from 18 to $220 \mu \mathrm{m}$, and there are several pores with a width of $50-100 \mu \mathrm{m}$. For the design of the 30V-10RHA blend yields a $98 \mu \mathrm{m}$ pore width. The 
higher the percentage of foam in the concrete, with the more significant the bubble diameter, so that the particles on the concrete are closer together when testing the slump flow. This causes the higher percentage of foam in the concrete, the higher the degeneration current. The results of the specific gravity test show concrete with a $30 \%$ foam percentage yielding maximum density between the other mixtures. Medium-specific gravity is present in concrete with a percentage of $60 \%$ foam. Seen from the bubble/air void microstructure is getting more prominent with the volume of other materials with air. The results of concerted foaming microstructural tests, a $10 \%$ substitution of RHA on semen gave the most solid microstructure of the bubble, especially in the percentage of $30 \%$ foam, the minimum number of pores, and the additional pore diameter with other RHA substitution percentages. SEM test results show the higher percentage of foam, then the resulting bubble diameter will be bigger, and more coincide and the increasing pore width. Conversely, the lower the percentage of the foam, the bubble the resulting diameter will be smaller.

\section{ACKNOWLEDGMENTS}

The research presented in this paper was supported by a grant from Unggulan Kompetitif Universitas Sriwijaya, 2017.

\section{REFERENCES}

[1] Bing, Lau Yih, Effect of Foamed Concrete with Egg Albumen, Faculty of Civil and Environmental Engineering, University Malaysia Pahang, 2010.

[2] Habeeb, G.A., Fayyadh, M.M. "Rice Husk Ash Concrete: the Effect of RHA Average Particle Size on Mechanical Properties and Drying Shrinkage." 2009.

[3] Hilal, Ameer A., Properties and Microstructure of Pre-formed Foamed Concretes, Ph.D. thesis, University of Nottingham., 2015. The United Kingdom.
[4] Hamad, Ali J. "Materials, Production, Properties and Application of Aerated Lightweight Concrete: Review," International Journal of Materials Science and Engineering Vol. 2, No. 2. 2014.

[5] Kamsiah, Mohd Ismail., Fathi, Mohamad Shazli., Manaf, Norpadzlihatun. "Study of Lightweight Concrete Behavior." 2004. Malaysia.

[6] Karthikeyan, B., Selvaraj, R., Saravanan, S., "Mechanical Properties of Foam Concrete," International Journal of Earth Science and Engineering,g Volume 08, No. 02. 2015

[7] Patchara On prom, Krit Chaimoon, and Raungrut Cheerarot. "Influence of Bottom Ash Replacements as Fine Aggregate on the Property of Cellular Concrete with Various Foam Contents.” 2015. Thailand.

[8] Ramezanianpour, A. A., Khani, M. Mahdi. Ahmadibeni, Gh. "The Effect of Rice Husk Ash on Mechanical Properties and Durability of Sustainable Concretes," International Journal of Civil Engineering. Vol. 7, No. 2. 2009.

[9] Reddy, D. V, and Alvarez, Marcelina, "Marine Durability Characteristics of Rice Husk Ash-Modified Reinforced Concrete," Fourth LACCEI International Latin American and Caribbean Conference for Engineering and Technology (LACCET'2006), 2006.

[10] Ruiwen, Kong, Properties of High-Strength Foam Concrete, Ph.D. thesis, National University of Singapore., 2003.

[11] Thakrele, Maheshkumar H., "Experimental Study on Foam Concrete," International Journal of Civil Engineering Research, Vol. 4, 2014.

[12] Tuan, Nguyen Van., Properties Rice Husk Ash as a Mineral Admixture for Ultra-High-Performance Concrete, Master of Engineering, National University of Civil Engineering Geboren te Thái Bình, 2011, Vietnam.

[13] Zhongwei Liu, Kang Zhao, Chi Hu, and Yufei Tang. "Effect of Water-Cement Ratio on Pore Structure and Strength of Foam Concrete," 2016, China.

[14] Hadipramana, Josef, Samad, Abdul Aziz Abdul., Zaidi, Ahmad Mujahid Ahmad., Mohammad, Noridah, Riza1, Fetra Venny. "Effect of Uncontrolled Burning Rice Husk Ash in Foamed Concrete," 2013, Malaysia.

[15] Zaidi, Ahmad Mujahid Ahmad., Hadipramana, Josef., Samad, Abdul Aziz Abdul., Mohammad, Noridah., Riza1, Fetra Venny. "Potential of RHA in Foamed Concrete Subjected to Dynamic Impact Loading." 2013. Malaysia.

[16] Freccy R., Anis S., Cher S. T., Yee L. L., \& Mahmood M. Tahir (2017). Splitting Tensile Strength of Lightweight Foamed Concrete with Polypropylene Fiber. International Journal of Advanced Science Engineering Information Technology, 7(2), pp. 424-230 